\title{
THE COMPLEMENTARY ROLE OF BUDGETING AND SCHOOL MISSION TOWARDS THE SUCCESS OF DYSFUNCTIONAL SCHOOLS
}

\author{
Molefi George Mosala Malefetsane Alphons Mofolo \\ Department of Education Studies, Marematlou Training Institute, South Africa \\ Senior Lecturer, Department of Management and Governance, Walter Sisulu University, South Africa
}

\section{ARTICLE INFO}

Received: 26 December 2021

Revised: 20 February 2022

Accepted: 21 February 2022

Keywords:

School Mission,

Dysfunctional Schools,

School Budget.

Corresponding Author:

Molefi Mosala

Email: mosalageorge1@ gmail.com Copyright (C) 2022 by Author(s)

This work is licensed under the Creative Commons Attribution International License (CC BY 4.0). http://creativecommons.org/licenses/ by/4.0/

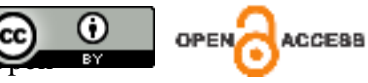

\begin{abstract}
Purpose: This article investigates the connection of budgeting and the mission of schools which could lead to the success of dysfunctional schools, and establish whether the school management teams are capable enough in developing a realistic mission of the schools in line with the budget.

Approach/Methodology/Design: The purposeful sampling was employed drawing 131 participants from forty schools. Both qualitative and quantitative data collection techniques were used by distributing questionnaires and conducting interviews. Descriptive statistics were primarily used to organize, analyze, summarize and interpret collected data through the application of mathematical procedures.

Findings: It is revealed that knowledge of developing a realistic schools mission and budget is inadequate in some public schools; This results in dysfunctional schools which are clouded by fragmentation of budgeting and mission operating parallel to each other. This is attested by the level of contradictions of SMTs and human resource officials in meeting the basic educational needs, such as the acquirement of learner/teachers support materials and maintenance of dilapidated infrastructure. Learners are left stranded without learning support materials and conducive learning environments. Consequently, quality education is compromised denying learners better education and future enshrined in most schools' mission statements.

Practical Implications: What is crucial in modern times, that being meticulous budgeting, capacity building on budgeting, financial and project management as well as a unified and modeling mission in all school activities and a refusal to tolerate dysfunction.

Originality/value: The study investigates a crucial problem; the reasons behind dysfunctional schools. There are contradictions between budgeting and school mission statements, mostly leading to dysfunctional performance.
\end{abstract}

\section{INTRODUCTION}

Disconnection of budgeting and the mission of schools is considered as one of the main reasons that could lead to dysfunctional schools. In terms of Section 20 of the South African Schools Act (SASA), it stipulates that the school governing body (SGB) and school management team (SMT) must develop a mission statement for the school (South Africa, 1996). However, before a school can formulate its mission, all stakeholders need to have a shared vision of what the school should achieve (Seeli, 2013). This vision then needs to be translated into a mission statement of the school (Preez., et al, 2003). The mission statement 
should not only be compatible with the vision but should be reflected in the budget and daily operational objective of the school. Budgeting, in this sense, reflects the mission of the school in monetary terms. Botha (2012) purports that in the adoption of a budget and a mission statement for a school, the legal requirements must be considered in conjunction with the Bill of Rights, Chapter 2 of the Constitution.

The budget is not a once-off activity or one-time plan, it is a dynamic document that requires planning and continuous monitoring to maintain control and provide feedback for the flexibility necessary in a school. Therefore, the budget should be planned and adapted to suit the unique character and needs of a particular school (Mosala \& Mofolo, 2016). Usually, the drafting of a budget is preceded by the planning of a school's vision and mission, which encourages all stakeholders to participate through the processes (Sorenson\&Goldsmith, 2018).

According to Kruger and Van Deventer (2003), the existence and functionality of a school are centered around its mission. The mission justifies the legitimate boundaries of a school's purpose and makes a clear distinction between one school and another. Hence, Kruger and Van Deventer (2003) regard the mission as the fundamental pillar that embraces school composition, meaning that the mission of the school should respond to the needs and expectations of learners, teachers, parents, society, and the economy.

In a research study by Pretorius (2014), it was revealed that effective schools are striving towards the attainment of their mission. Contrary to Pretorius, Mawdsley et al. (2015) argue that some schools become dysfunctional as soon as they fail to accomplish their mission. In addition, Xaba (2011) asserts that certain schools' budgets are not addressing schools' needs or their mission. This suggests that the mission and budget operate in isolation, which then ultimately fails in accomplishing the desired goals.

This article investigates the connection between budgeting and mission statement and establishes whether the school management teams (SMTs) are capable enough in developing a realistic mission of the school in line with the budget towards the success of public schools in the Eastern Cape Province, Alfred Nzo West District. The Eastern Cape is one of the provinces in South Africa, ranked third from the bottom regarding matric (Grade 12) results of 2021. The majority of schools in this province are considered dysfunctional, based on poor academic results. This article provides recommendations to the SMTs and the Department of Basic Education (DoBE) in South Africa.

\section{LITERATURE REVIEW}

\section{The mission of a school}

The (SASA) 84 of 1996 article 20(1b) empowers the SGB and SMT to be able to develop the mission statement of any school (South Africa, 1996). The mission of a school is all about values and philosophy and is underpinned by statements that clearly show the aspirations of the school, relating to quality education. However, once the mission is developed, the challenge remains to establish it in action and keep it functional. Hence, the functionality of the schools' mission depends on the availability of funds and proper budgeting. Together, the mission and budget could be described as the engine of all schools and should complement each other (Blankstein, 2010).

Astonishingly, research by Xaba (2011) revealed that in some schools, budgeting processes are not necessarily authentic, realistic and lack transparency as the budgets are completed for compliance with departmental requirements and therefore neglect the needs of the schools. 
Mission statements are developed out of desperation and not inspiration, lacking depth and relevancy towards school development (Modiba, 2001). The sentiments of Xaba, Blankstein, and Modiba justify that it is clear that the mission and budget of schools are not complementing one another. These authors imply that the mission and budget are not aligned, but each aspect operates in isolation, which then ultimately fails in accomplishing desired goals.

\section{Dysfunctional schools}

According to Mawdsley et al., (2015), dysfunctional schools are "failing schools" that are producing negative results and failing to accomplish the purposes for which they were created. It should be noted that in such cases, the management of schools can be described as chaotic, clouded with poor planning, with fingers pointing out the failures to others. These result in shifting the blame due to poor management and results.

In South Africa, the success of a school is measured against an established point, both in primary and secondary schools. Failure to obtain the appointed percentage results in being regarded and classified as underperforming or dysfunctional by the National and Provincial DoBE. The spokesman of basic education in South Africa, Elijah Mhlanga cited in Roets (2015), was against the use of the term 'dysfunctional schools'. He argued that the word 'dysfunctional schools' is destructive and a demoralizing classification. In defending his argument, Mhlanga preferred the use of words such as low-performing schools, ineffective schools, and at-risk schools, denoting that these schools are underperforming schools.

Although the word dysfunction can have different meanings and take different forms in different schools and different contexts, Omar et al., (2018) and Bergman (2013) purport that the word "dysfunctional" insinuates similar interpretations and indicators across institutions. It is thus applicable to the perspective in which it occurs. Therefore, the term dysfunctional will be considered appropriate in this research.

The viewpoint of the Annual National Assessment (ANA) concurs with Omar et al., and Bergman in the previous paragraph by confirming that the percentage of learners performing at adequate levels in literacy and numeracy is unacceptably low, reflecting, to a large extent, the ineffective management and dysfunctionality (DoBE, 2011). This is particularly noticeable in townships and rural schools (DoBE, 2011). Roets (2015) agrees with the ANA accentuating that "It is no secret that black children suffer more when it comes to education because the most dysfunctional schools are those in the townships and rural areas where a lack of facilities and resources are found"( p.3). Furthermore, Roets (2015) regarded racial inequalities as instrumental in dysfunctional schooling in South Africa. He attested that the functionality of schools has been negatively affected by lack of resources, stigmatized with an obstinate culture of failure, and failure to accomplish the mission statement.

Pretorius (2014) research conducted in Eastern Cape schools, revealed that the South African Democratic Teachers Union reiterated that "Colonialism and apartheid created miserable conditions in schools; until there is redress and equality, there is nothing we can do"( p. 62). However, can schools keep on holding onto the past injustices liable for the state of the dysfunctionality in schools' ad infinitum? Arguably, this researcher petitioned that "If dysfunctional schools were to be turned around, the South African education system should spend vast amounts and time on training SMTs at all levels of the system" (Pretorius, 2014, p. 63). 
Grant et al. (2010) rubberstamped Roets and Pretorius' stance in the two paragraphs above, indicating that the social context has a direct effect and influence on the functionality of schools, especially in poor communities. Grant et al. bemoan that the dysfunction in many of the township and rural schools, post-1994, has continued despite government attempts to redress imbalances of the past and restore a culture of teaching and learning. They pointed out that many schools located in disadvantaged communities had inherited a legacy of dysfunction, yet some have succeeded in achieving the envisaged target percentage as prescribed by the Department of Basic Education (DoBE), despite the odds.

Jansen (2012) contends with the above arguments and completely agrees with the last statement of Grant et al. (2010). Jansen argues that the functionality and success of schools are not affected and determined by their surrounding socio-economic context. Jansen's arguments are buttressed by the findings of the gathering of principals and senior teachers from rural and disadvantaged communities in South Africa on Friday the $13^{\text {th, }}$ 2012. Jansen (2012) reveals that principals and senior teachers were asked the following questions in that gathering: "You produced the best academic results of all the under-resourced schools, why does your school succeed when almost every other school with your socio-economic profile fails?"( p.2). The answers from the principals and senior teachers were that "There is a strong and singular sense of mission in our schools - the children come first. We plan to achieve our own goals such as productive teaching and learning".

Grant et al. (2010) assent to a certain extent with Jansen by describing those schools as being meticulous in using scanty resources effectively and efficiently to their advantage. Those schools are characterized by efficient and effective management of their school budget with one goal in mind "the children come first". Consequently, Pretorius (2014) added by saying that in most instances a functional school has staff and parents who are united and understand their mission to deliver quality and excellent education.

On the other hand, Weeks (2012) found dysfunctional schools obstructing, rather than facilitating learning and teaching. Contrary to Jansen (2012), Weeks (2012) argues that dysfunctional schools are significantly associated with a broken culture of learning and teaching, no sense of mission, no clear goals, and poor pass rates. When one considers the above arguments, schools become dysfunctional in the instance they fail to accomplish their mission and, in most cases, there is no commitment (Mawdsley et al., 2015). According to Seeli (2013), team building enhances school functionality, though one can start to understand that teamwork and parental involvement in dysfunctional schools are non-existent (Reynolds, 2010).

In functional schools, the mission is utilized as a driving mechanism towards the achievement of quality, relevance, and excellence in education that produces competent learners desired by society and the job market. The mission statements symbolize a beacon of hope and promise, guaranteeing a successful and healthy school environment that supports each learner's academic, social, physical, and emotional development (Jansen, 2012). Contrary to the above assertions, Modiba (2001) states that clear evidence confirms the point that the dysfunctional schools do not know where to begin when they have to develop a mission statement, and if it exists, it is not functional. He further purports that any mission statement should not be envisaged to be a hidden document that is only known to a few in any school.

A mission statement must be formulated as inclusive as possible, an effective working document and consider the future of learners. Such a practice could prevent a situation where the stakeholders do not have knowledge and a sense of urgency and ownership towards the 
mission statement. It should also be born in mind that schools are unique, therefore the missions for different schools will differ, by addressing specific needs.

\section{Budgeting}

Blankstein (2010) mentions that some schools tend to use generic, vague, and meaningless mission statements. The budget exhibits the mission of the school in monetary terms. Therefore, the mission can only be achieved once the funds are available and allocated towards set goals. Because funds of any school are limited, priorities must be determined (Botha, 2012). For this very reason, it is ideal for a school to draw up a budget.

The important point about budgeting is that it is not solely, or even mainly, about money. Budgeting provides an opportunity to express the goals and mission of the school in financial terms. It is the very heart of financial management. It is more than the presentation in figures of anticipated expenditure and revenues for a given financial period. It is an important financial management tool for setting objectives, measuring progress, and identifying weaknesses (Mestry, 2016).

According to SASA, the budget represents the legal authority to receive income and spend money. It is considered the definitive policy document. Adoption of a budget in a school implies that a set of decisions have been made by the SGBs and SMTs that culminates in matching a school's resources with its needs. As such, all school stakeholders are obligated by law to adhere to and comply with the approved budget (Odden \& Picus, 2008). Mestry (2016) advises the SGBs and SMTs that for the budget to be effective and well functional, it is dependent on realistic planning and implementation. Schools can then determine priorities and financial alternatives in achieving set goals. Notably, it is the responsibility of the SMTs and SGBs throughout the school improvement plan and action plan to gather information for use in constructing the budget (Sorenson \& Goldsmith, 2018).

For the budget to be successful; planning, implementation, analysis, and review processes should be followed and adhered to (Sorenson \& Goldsmith, 2018; Botha, 2012; Kruger \& Van Deventer, 2003). Planning starts with the acknowledgement and engagement of stakeholders in an open communication platform (Blase et al., 2010). Using this platform, the SMTs should clarify requirements and procedures such as how to submit inputs, dates, and how decisions will be made. According to SASA, the budget should be in line with the goals, values, priorities, and missions for the local education district and of that particular school.

One rather effective strategy normally employed to collect data is the budget file that assists in referencing items and information that should be considered when preparing the budget for the coming year (Blase et al., 2010). During this process, some items may serve only as reminders, whereas others will provide basic data that can be used in the preparation of the next budget. Another strategy that may prove helpful is a checklist of items that should be considered during planning and evaluation.

At the end of the year, the budget is analyzed and evaluated for its effectiveness in attaining the local education district and particular school's goals and missions (Clarke, 2012; Sorenson \& Goldsmith, 2018). Analysis typically involves an examination of how funds were used, what outcomes resulted from the expenditure of these funds, and to what degree the outcomes achieved the objectives stated during the planning phase. This evaluation phase is important in determining the 'following year's budgetary allocations (Sorenson \& Goldsmith, 2013). Thereafter, the budgets are reviewed to ensure that they correspond with the requirements of set goals and missions (Coleman \& Anderson, 2000). 
In the final analysis, the school budget should support the mission of the school and the school improvement plan to rescue dysfunctional schools (Harris \& Chrispeels, 2006; Baker, Green \& Richards, 2008).

\section{METHODOLOGY AND PROCEDURES}

To obtain the objective of this research, ethical considerations were observed. Permission was requested and granted by Marematlou Training Institute, the awarded training tender for school managers in Eastern Cape (2018 to 2019), and the Department of Education Alfred Nzo West. The researcher followed standard procedure and informed participants about the objectives of the study, the voluntary nature of their participation, and ensured anonymity.

The research approaches considered to be relevant for this study are both qualitative and quantitative methods, generally known as mix-methods or triangulation (Lichtman, 2011). Therefore, it is assumed that quantitative (questionnaires) and qualitative (interview) methods would complement each other in bringing about a meaningful research finding.

The introduction showed that the focus of this research is centered around public schools, as it was discovered that they are facing serious performance challenges due to non-alignment and functionality between the mission and the budget. Therefore, the participants were drawn from the rural, township, and urban primary and secondary public schools in Alfred Nzo West District, having a background of producing a poor record of results.

The researchers employed purposeful sampling because they aimed to receive information from participants who were deemed richly informed and experienced in drafting their schools' budgets and mission statements. The participants who formed the unit of analysis of this article were drawn from forty (40) schools from the rural, township, and urban primary and secondary public schools. The sample was drawn from 40 principals, 40 deputy principals, 50 heads of departments (HODs), and one HR district official. These people were regarded to contribute positively to this study. This data is presented in Table 1 below.

Table 1: Research population

\begin{tabular}{|c|c|c|c|}
\hline Population & $\begin{array}{l}\text { Distributed } \\
\text { Questionnaires }\end{array}$ & $\begin{array}{l}\text { Completed } \\
\text { Questionnaires }\end{array}$ & $\begin{array}{l}\text { Not } \\
\text { Completed } \\
\text { Questionnaires } \\
\end{array}$ \\
\hline Principals & 40 & $36(90 \%)$ & $4(10 \%)$ \\
\hline Deputy Principals & 40 & $28(70 \%)$ & $12(30 \%)$ \\
\hline Head of Departments (HODs) & 50 & $40(80 \%)$ & $10(20 \%)$ \\
\hline Total & $\begin{array}{l}130 \\
\text { Interview }\end{array}$ & $\begin{array}{l}104(80 \%) \\
\text { Conducted }\end{array}$ & $\begin{array}{l}26(20 \%) \\
\text { Not } \\
\text { Conducted }\end{array}$ \\
\hline Resource Official & 1 & $1(100 \%)$ & 0 \\
\hline Total & 1 & $1(100 \%)$ & $\mathbf{0}$ \\
\hline
\end{tabular}

Table 1 shows a total sample of 131 participants. Therefore, 130 questionnaires were distributed to them. From table 1, the statistical information shows that forty (40) questionnaires were distributed to principals, the other forty (40) to deputy principals, and fifty (50) to HODs. Out of 130 questionnaires distributed, 104 were completed, while 26 were not completed, which constituted a response rate of $80 \%$. One HR official was interviewed. 


\section{Data collection and analysis}

The instruments that were employed to collect the data in this article were questionnaires and an interview. The questionnaire was the instrument through which data was collected. Then, the interview with the HR official was conducted as well to give clarity on certain questions posed in the questionnaire and to consolidate data collected through the questionnaire. In this process of research, the researchers used descriptive statistics primarily to organize, analyze, summarize, and interpret collected data through the application of mathematical procedures (Check \& Schutt, 2012). The researchers then established patterns of similarities, differences and revealed their diversity. This assisted in establishing the importance of the connection between budgeting and mission statements in public schools.

\section{RESULTS AND DISCUSSION}

Table 2 Drafting of schools' budget

\begin{tabular}{llll}
\hline $\begin{array}{l}\text { Knowledge of drafting } \\
\text { schools' budget }\end{array}$ & Principals & $\begin{array}{l}\text { Deputy } \\
\text { principal }\end{array}$ & HODs \\
\hline No knowledge & 4 & 7 & 13 \\
Limited knowledge & 32 & 21 & 25 \\
Have knowledge & & & 2 \\
\hline
\end{tabular}

Source: Authors

Table 2 shows the knowledge of drafting schools' budgets. As far as SMTs are concerned, four (4) questionnaires completed by the principals, seven (7) by the deputy principals, and sixteen (16) by the HODs indicated that they do not know how to draft their school's budget and their schools' funds are normally exhausted during the second term. Furthermore, six (6) HODs indicated that "school budget is drafted by the principal and clerks and we were not involved". On the other hand, thirty-two (32) questionnaires completed by other principals, twenty-one (21) deputy principals, and twenty-five (25) HODs indicated that when drafting the budget, they involved the SMT and SGB and considered paper budget as well as the schools' needs with the help of the INCOM. Impressively, two (2) HODs indicated that they are knowledgeable when drafting the budget, they considered the Public Finance Management Act and checked learners' enrolment.

Table 3 Development of mission statement

\begin{tabular}{llll}
\hline $\begin{array}{l}\text { Knowledge of developing } \\
\text { the mission statement }\end{array}$ & $\begin{array}{l}\text { Principal } \\
\text { s }\end{array}$ & $\begin{array}{l}\text { Deputy } \\
\text { principal }\end{array}$ & HODs \\
\hline $\begin{array}{l}\text { No knowledge } \\
\text { Limited knowledge }\end{array}$ & 10 & 9 & 8 \\
Have knowledge & 3 & & \\
\hline
\end{tabular}

Source: Authors

Table 3 shows the knowledge of developing the mission statement. Ten (10) principals, nine (9) deputy principals, and eight (8) HODs indicated that they had no idea how the mission statement is developed. On the other hand, three (3) principals indicated that they have limited knowledge "when we arrived at that school we found that the mission statement was there already and it is operational till now". In contrast, twenty-three (23) principals, nineteen (19) deputy principals, and thirty-two 32 HODs indicated that they know how to develop a mission statement. They highlighted that they involve all stakeholders outlining the aims of the school, the expectation of the school, and the needs of the community. One HOD indicated that they consider policy guided by (SASA), involve business sectors, consider the geographical position of the school, as well as the employment rate. 
Table 4 Functionality of mission and the budget

\begin{tabular}{llll}
\hline $\begin{array}{l}\text { Factors contributing to non-functionality of } \\
\text { mission and the budget }\end{array}$ & Principals & $\begin{array}{l}\text { Deputy } \\
\text { Principal }\end{array}$ & HODs \\
\hline Insufficient funding & 22 & 9 & 22 \\
Late allocation of funds by DoBE & 22 & 9 & 22 \\
Lack of knowledge & & & 2 \\
Negative attitude & & & 2 \\
Hidden known by individuals & 6 & & 2 \\
Logistics of committed funds & 8 & 19 & 18 \\
Well functional mission and the budget & & & \\
\hline
\end{tabular}

Source: Authors

With regards to the factors that contributed to the non-functionality of the mission and the budget. Table 4 shows twenty-two (22) principals, nine (9) deputy principals and twenty-two (22) HODs indicated that due to insufficient funding and late allocation of funds by DoBE, they experienced certain problems about the functionality of the school budget and mission statement. Accounts such as telephone, electricity and municipality bills are not paid in full, and schools are forced to deviate from the budget and take money from other allocations to manage situations such as school assessments. Due to insufficient and late allocation of funds, academic and non-academic activities are performed below expected standards. Consequently, this compelled schools to embark on extensive fundraising, which could disrupt learning and teaching.

While on the other hand, two (2) HODs indicated that negative attitudes and lack of understanding among stakeholders contribute to the dysfunctionality of the mission and the budget. Furthermore, they indicated that some mission statements are in the principals' office gathering dust while others are posted on walls but they rarely revisited, review and guide the school. They are too safe and too easily forgotten.

Six (6) of the principals indicated that they were unable to always utilize the budgeted schools' funds because the district officials kept on telling them about the logistics of the financial circle against academic circle (committed funds), ring-fencing, management of grants (nutrition) and assets. Concerning circles, the SMTs should take note that in South Africa academic year circle starts in January and ends in December. The financial year circle starts in April and ends in March of the following year. The committed funds are utilized within the financial year circle and failure to utilize the school funds results in forfeiture. The principal or SMTs are then held accountable for the unused funds. Ring-fencing means restricted utilization of budgeted and donated funds for other reasons and may even use shifting of funds for other activities. To utilize ring-fenced funds, it should be done via proper application and approval from the DoBE authority. Inventory management entails the systematic and periodic physical verification of assets recorded in the asset register. Astonishingly, eight (8) principals, nineteen (19) deputy principals and eighteen (18) HODs indicated that there is a correlation and functionality between the mission and budget in their schools.

The findings in Tables 2, 3 and 4 revealed an acute disparity of a functional mission statement and budgeting in schools. For instance, the above exposition shows that there is no corroboration among responses it then becomes evident that SMTs are lost when coming to comply with the mission and budget principles and procedures.

Table 5 Factors contributing to schools' poor performance

\begin{tabular}{llllll}
\hline $\begin{array}{l}\text { Factors contributing } \\
\text { performance } \\
\text { Lack of funds }\end{array}$ & schools' & Principals & $\begin{array}{l}\text { Deputy } \\
\text { Principal }\end{array}$ & HODs \\
\hline
\end{tabular}




\begin{tabular}{|c|c|c|c|}
\hline Lack of LTSM & 33 & & \\
\hline Lack of learner's transport & & 22 & \\
\hline Dilapidated schools' infrastructure & 33 & & 9 \\
\hline No laboratories and libraries & 33 & & \\
\hline Misplacement of teachers & & & 31 \\
\hline Poor communication & & & 31 \\
\hline Inconsistent disciplinary measures & & & 9 \\
\hline Poor human relation & & & 31 \\
\hline $\begin{array}{l}\text { Lack of commitment from the parents, } \\
\text { learners, teachers and district officials }\end{array}$ & 3 & 6 & \\
\hline
\end{tabular}

Table 5 shows thirty-three (33) questionnaires completed by principals revealed that the main causes of poor performance in their schools is because of lack of LTSM, insufficient and dilapidated classrooms, no laboratories and libraries, as well as lack of funds to pay SGB posts and other service providers. On the other hand, three (3) questionnaires completed by other principals indicated that in their schools there is no dedication and commitment from the learners, teachers and parents towards school work. The majority of the deputy principals twenty-two (22) indicated that performance is dented by poor learners' attendance due to the long distance from home to school and lack of learners' transport. Other six (6) deputy principals disclosed that district officials are seldom visiting and assisting the schools; parental involvement is not maximized at their schools; it is exacerbated by uneducated parents unable to assist learners with school work.

Furthermore, thirty-one (31) HODs indicated fundamental causes of poor results including poor human relations, teachers teaching subjects that they are not qualified to teach, lack of communication. However, nine (9) HODs indicated factors such as the overcrowded of learners in classes, as well as learners' behavioral problems/poor discipline. Surprisingly, two (2) HODs indicated that learning and teaching take place under trees and dilapidated buildings. They further highlighted other factors such as lack of water and no ablution facilities in their schools, "the current ones are full and learners normally fall into pit toilets and sadly in 2018, a learner died in a pit toilet".

Concerning shortage of LTSM, teaching and learning under the tree, ablution facilities and death of a learner in a pit toilet, the South Africa Bill of Rights (Chapter 2 of the Constitution) was violated when considering the operational conditions in Eastern Cape schools. To mention a few, the Bill stipulates that everyone, including learners and teachers, has the right to learn, equality, human dignity and fair labor practices (Motshega, 2017). The above responses justify the quality education, equality and human dignity enshrined in most schools' missions are not observed and pragmatic. To this end, Ngcukana (2019) points out that pit toilets are a nightmare in Eastern Cape schools because of irregular acts at the site of DoBE. Schools have turned into death traps for learners and teachers and are not seen as institutions for hope and learning. Therefore, the mission and passion for learning and teaching is tarnished. Fear is that if drastic measures such as accountability are not taken and implemented, poor performance at schools can worsen while the guilty individuals are getting off scot-free without any consequences.

The above-mentioned factors are highly regrettable reflect no sense of urgency, respect for the future of learners, and fragmentation on the common goal between the SMTs and the DoBE. There is no common mission and in the end, learners are denied quality education. Respondents confirmed that teachers, parents and DoBE contribute less, ensuring that schools produce the best quality results. These all undoubtedly contribute to the dysfunctionality of schools. 
Table 6 Strategies to improve results

\begin{tabular}{llll}
\hline Strategies & Principals & $\begin{array}{l}\text { Deputy } \\
\text { principal }\end{array}$ & HODs \\
\hline Extra classes and cluster teaching & 30 & 9 & 13 \\
Incubation of learners and matric camps & 33 & 17 & 24 \\
Employ financial clerks & 33 & 9 & 13 \\
Request printing and furniture from & & 9 & 13 \\
other schools & 6 & & \\
Consistent analysis of results & 6 & & \\
Accountability meetings & 6 & & 24 \\
Team building activities & & 17 & 24 \\
Procure school governing body posts & & 17 & 24 \\
Mentoring programs & &
\end{tabular}

Source: Authors

Table 6 shows the strategies that can improve results in the schools. Thirty (30) principals, nine (9) deputy principals, and thirteen (13) HODs indicated that they employed extended programs such as extra classes in the morning, afternoon, weekend, holidays, incubation of learners in hostels; and holding matric camps during examinations for learners to catch up and improve results. Furthermore, they requested DoBE to employ school financial clerks, requested printing copies and furniture from schools that have extra. Surprisingly, the same respondents indicated that the mentioned strategies are not carried out and some strategies collapse before implementation because of lack of planning, supervision, commitment, and funds to sustain the programs.

On the contrary, six (6) principals which is the minority added by indicating that they are consistent in results analysis; they hold accountability meetings for teachers every Friday; they asked guru teachers to assist, and use team building and awards to motivate learners and teachers. However, three (3) HODs indicated that they established reading clubs, spelling competitions, monitored curriculum coverage while intensifying Language of Learning and Teaching, conducted class visits, and encourage revision work. Then, seventeen (17) deputy principals and twenty-four (24) HODs recommended that rural allowance be provided to teachers who are teaching in deep rural areas so that they do not leave teaching; secure SGB post; consistent mentoring of SMTs; team teaching, twinning, and clustering of schools.

Table 7 Areas that need training

\begin{tabular}{llll}
\hline Areas that need training & Principals & $\begin{array}{l}\text { Deputy } \\
\text { Principal }\end{array}$ & HODs \\
\hline School finances & 23 & 19 & 27 \\
School budget & 23 & 19 & 27 \\
Developing mission statement & 9 & 7 & 11 \\
School governance & 9 & 7 & 11 \\
No need training & 4 & 2 & 2 \\
\hline
\end{tabular}

Source: Authors

With regard to areas that need training Table 7 shows the majority of SMTs twenty-three principals, nineteen deputy principals and twenty-seven HODs indicated that the DoBE did not ask them about their weaknesses when organising training and considering their personal growth plan. Their preference of training is on school finances, specifically on the drafting of schools' budgets, and schools' finances. On the other hand, nine (9) principals, seven (7) deputy principals, eleven (11) HODs indicated that they preferred to be trained in developing a vision and mission statements, and school governance. On the contrary, four (4) principals, two (2) deputy principals and two (2) HODs indicated that they do not need training. 
Finally, the interviews conducted with the HR district official revealed that the district is concerned about the dysfunctionality of their schools and assisted schools by providing marathons of workshops. The district official mentioned that "the district is handling a number of cases of mismanagement of school funds from the site of SMTs. Finances are a mess at schools. Funds are deviated from budget allocations and used for the secondary purposes like renovation of principal office and fancy curtains in staffroom rather LTSM. Their budget is not talking to their school improvement plan. Some SMTs and SGBs are pushing their own personal agendas when budgeting neglecting the needs of learners". The $\mathrm{HR}$ further indicated that strong and competent management is lacking in most of the district schools.

The findings revealed that knowledge of developing a realistic schools' mission and budget is inadequate in some public schools resulting in the dysfunctional schools which are clouded by fragmentation of budgeting and mission operating parallel to each other. This is attested by the level of contradictions of SMTs and HR officials in meeting the basic educational needs, such as the acquirement of LTSM and maintenance of dilapidated infrastructure. Learners are left stranded without learning support materials and conducive learning environments. Consequently, quality education is compromised denying learners better education and future enshrined in most schools' mission statements.

\section{Discussion}

It is evident from the above findings that the Eastern Cape education system is largely grappling in vain with the need to provide good quality education for learners. To this end, large numbers of schools in the Alfred Nzo West District are deemed justifiably dysfunctional. According to Roets (2015) and Pretorius' (2014) the politicians, parents, teachers, and media have ascribed this situation to a plethora of reasons.

From the findings, one can surmise that Eastern Cape public schools, particularly rural and township schools, have not yet found a firm footing on the matter of budgeting and mission statement. Evidence to this assertion is lack of LTSM; dilapidated and lack of classrooms, laboratories, libraries, toilets; fragmented SMTs; and high learner failure rate. Most of the schools in Alfred Nzo West District are 'no-fee' paying schools and they depend on the allocation from the DoBE for survival.

It is evident from the interviews conducted with the HR district official that the training received by the SMTs is insufficient because it is designed in workshop patterns as informative sessions. The district official mentioned that "Finances are a mess at schools. Their budget is not talking to their school improvement plan". According to Botha (2012) the budget should be proactively prepared in a planned, accurate and survey-able manner to achieve the schools' plans. Xaba's (2011:207) rubberstamped HR official view reveal that "funds have deviated from budget allocations". The view of this official are supported by the SMTs' responses, indicating repeatedly that they need specific and strategic training on school financial management, the focus being on the drafting of the school budget, and ringfenced finances. Although the above response is from an HR district official, they nonetheless provided important insights and indicators into what could be plaguing dysfunctionality in schools.

Given the above discussion, the researchers concur with Pretorius (2014) that dysfunctionality does not have to be the modus operandi for schools simply because schools are located in a dysfunctional area afflicted with socio-economic tantrums. Findings revealed that in the dysfunctional schools, the intervention strategies mentioned are not carried out with passion and precision by the SMTs, teachers, learners and parents. Again, poor planning, 
misunderstanding of set missions by stakeholders resulted in misuse of time and funds, and ultimately, poor results. Given these discussions, it is clear that the findings in this article provide a critical perception of the discrepancies that exist about the mission statement and budgeting processes in some schools of Alfred Nzo West District.

\section{CONCLUSION AND SUGGESTION}

The study aimed at investigating the connection of budgeting and the mission of schools, establishing whether the SMTs are knowledgeable in developing a functional mission statement of the schools' in line with the budget. Based on the results, it is concluded that a good mission statement should provide a realistic, credible, and attractive picture of a school in the future. This alludes that the mission of the school should be clearly understood by all stakeholders preferably be in their language, visible, displayed at schools' foyer, translated into daily learning and teaching activities, as well as being delivered by SMT and teachers. However, because the mission statement is dynamic, the mission will change with compelling changing circumstances. No school can achieve its mission without the support of a realistic budget. As shown in the literature, the effective and realistic budget must be well-communicated, well-drafted taking into consideration of the income, expenses, adjusting habits if necessary, monitoring, evaluation, accountability, and strictly adhered to, yet accommodating contingencies.

Moreover, most of the intervention strategies such as extended programs, incubation, learning camps and extensive funds raising activities are project-orientated activities. It is critical, therefore, that the SMTs should to take the lead and have project management skills based on financial management, planning (budgeting), strategic management, and risk management to bring success in such extended programs and improvements in their schools. Significantly, it become clear from the findings that continuous training is fundamental and a must for the SMTs, particularly on developing the schools' mission statements, budget, and effective communication.

The dysfunctional schools can benefit through the utilization of South African Broadcasting Commission (SABC) learning programs and also go digital through the assistance of mobile library and District Teacher Development Centres (DTDC) in improving performance and acclimatizing with the fourth industrial revolution. In a sense, a digital approach can address the problem of the shortage of LTSM by accessing online libraries provided by the publishing companies such as Oxford, MacMillan and others. What is sorely needed in Alfred Nzo West is on-site interaction, visible and hands-on circuit and district managers who are mentoring SMTs on the essence and implementation of schools' mission and budgeting towards the functionality of schools.

Consequently, it is apparent that blaming the socio-economic environment and the past will not transform dysfunctional schools. It is crucial that a school's budgeting is meticulous, contain a unified and modeling mission in all school activities and refusal to tolerate dysfunction. Most importantly, the key to the success and transformation of dysfunctional schools is bestowed on the fire of passion and curiosity lit by all school stakeholders believing in their ability to perform against all odds. Thereby not settling for mediocracy.

\section{ACKNOWLEDGEMENTS}

The researchers wish to thank the following people and instances: Dr. A Kolobe, Dr. W Smith for scholarly technical guidance through the writing of this article. Mr. N Zwele and Mr. M Chake for their noteworthy academic contribution. Colleagues at Marematlou 
Training Institute for their informal and mostly unconscious moral support! The Marematlou CEO Prof J Selesho and Eastern Cape Department of Education for the opportunity to conduct this research. All respondents honestly and reliably answered the questionnaire and interview.

\section{CONFLICT OF INTEREST}

There are no conflicts of interest with this paper.

\section{FUNDING}

The costs of conducting the study and publishing this article are of the authors.

\section{REFERENCES}

Baker, B., Green, P., \& Richards, C. E. (2008). Financing education systems. Pearson.

Bergman, M. M. (2013). What is a dysfunctional school? Africa Education Review, 10(2), 381-390. https://doi.org/10.1080/18146627.2013.812290

Blankstein, A. M. (Ed.). (2010). Failure is not an option $\circledR_{0} 6$ principles for making student success the only option. Corwin Press.

Blase, J., Blase, J., \& Phillips, E. (2010). Handbook of school improvement: How high-performing principals create high-performing schools. Corwin Press.

Botha, R. J. (2012). Financial management and leadership in schools. Pearson.

Check, J., \& Schutt, R. K. (2012). Research methods in education. London: Sage. https://dx.doi.org/10.4135/9781544307725

Clarke, A. (2012). The handbook of school management. Cape Town: Kate Mccallum.

Coleman, M., \& Anderson, L. (2000). Managing finance and resources in education. London: Sage. https://dx.doi.org/10.4135/9781446219683

Department of Basic Education (DoBE). (2011). Report on the Annual National Assessments of 2011. Pretoria: Department of Basic Education. Report on the Annual National Assessments of 2011 - DoBE

Du Preez, P., Campher, T., Grobler, B., Loock, C., \& Shaba, S. M. (2003). Effective education management series: Module 1. Principles of effective education management. Heinemann.

Grant, C., Jasson, A., \& Lawrence, G. (2010). Resilient KwaZulu-Natal schools: An ethics of care. Southern African Review of Education with Education with Production, 6(2), 81-99. https://hdl.handle.net/10520/EJC98992

Harris, A., \& Chrispeels, J. H. (2006). Improving schools and educational systems: International perspectives. London: Routledge. https://doi.org/10.1111/j.1467-8527.2007.367-5.x

Lichtman, M. (2011). Understanding and evaluating qualitative educational research. Singapore: Sage. https://dx.doi.org/10.4135/9781483349435

Mawdsley, R., Bipath, K., \& Mawdsley, J. L. (2015). Functional urban schools amidst dysfunctional settings: Lessons from South Africa. University of Pretoria: Pretoria. https://doi.org/doi/abs10.1177/0013124512449859

Mestry, R. (2016). The management of user fees and other fundraising initiatives in self-managing public schools. South African Journal of Education, 36(2), 1-11. https://doi.org/doi/abs/10.15700/saje.v36n2a1246

Modiba, S. N. (2001). The importance of vision and mission statements in promoting school effectiveness in Northern Province Schools. Thesis (PhD), University of Johannesburg, Johannesburg. uj:9394 http://hdl.handle.net/10210/5830

Mosala, G., \& Mofolo, M. A. (2016). Effective use of budgeting as a tool towards financial management in schools in Lejweleputswa District. Africa's Public Service Delivery \& Performance Review, 4(4), 389-409. https://doi.org/10.4102/apsdpr.v4i.121

Motshega, A. (2017). School infrastructure safety and security guidelines. Pretoria: Department of Education.

Ngcukana, L. (2019). Huge cost of pit toilets for school investigated. Johannesburg: City Press.

Odden, A. R., \& Picus, L. O. (2008). School finance: A policy perspective. New York: McGraw-Hill. 
Omar, R., Randa, B., Aya, M,A. (2018). Dysfunctional Behavior at the Workplace and Its Impact on Employees' Job Performance. International Journal of Business Administration ${ }_{2}$ 9(4):224. https://doi.org/10.5430/ijba.v9n4p224

Pretorius, S. G. (2014). Educators' perceptions of school effectiveness and dysfunctional schools in South Africa. J SocSci, 40(1), 51-64. https://doi.org/10.1080/09718923.2014.11893302

Reynolds, D. (2010). Failure-free education? The past, present and future of school effectiveness and School improvement. Routledge. https://doi.org/10.4324/9780203020234

Roets, E. (2015). South Africa's education system is often described as being in crisis. A recent claim suggests $80 \%$ of schools could be "dysfunctional".

Seeli, F. D. (2013). Managing ineffective secondary schools in Lejweleputswa District. Magister Education dissertation, Central University of Technology, Welkom.

Sorenson, R. D., \& Goldsmith, L. M. (2013). The principal's guide to school budgeting (2nd ed.). Pretoria: University of South Africa.

Sorenson, R. D., \& Goldsmith, L. M. (2018). The principal's guide to school budgeting (3rd ed.). Pretoria: University of South Africa.

South Africa. (1996). South African Schools Act, Act no 84 of 1996. Cape Town: Government Printers South African Schools Act, Act no 84 of 1996

Weeks, F. H. (2012). The quest for a culture of learning: South African school's perspective. South African Journal of Education, 32(1), 1-14. https://doi.org/doi/10.15700/saje.v32n1a565

Xaba, M. I. (2011). The possible cause of school governance challenges in South Africa. South African Journal of Education, 31(2), 201-211. https://doi.org/10.15700/saje.v3n2a479 